\title{
QUALITY AND THERMAL CHARACTERIZATION OF GLUTENIN- RICH FRACTIONS OF WHEAT FLOUR (TRITICUM AESTIVUM) OBTAINED BY DIFFERENT EXTRACTION METHODS
}

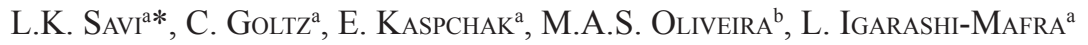 \\ and M.R. MAFRA \\ ${ }^{a}$ Department of Chemical Engineering, Federal University of Paraná, 81531-980 - Curitiba. PR. Brazil \\ ${ }^{b}$ Department of Biochemistry, State University of Maringá, Av. Colombo 5790, 87020-900 - Maringá. PR. Brazil
}

(Received: 12 November 2018; accepted: 9 February 2019)

Wheat gluten is mainly responsible for the structural characteristics of bakery products. When studying wheat proteins, it is important to use reliable extraction methods. Four different methods of wheat protein extraction were studied, with emphasis on the glutenin-rich fractions. The final quality of the protein fractions was evaluated in terms of denaturation, indirect yield, molecular weight, secondary structure, and thermal profile. Our results indicate that addition of dithiothreitol improves glutenin extraction without interfering with protein secondary structure and denaturation. Different thermal profiles were evidenced for different extraction methods, indicating the selectivity of the processes. Denaturation temperatures of the samples showed differences within about $3{ }^{\circ} \mathrm{C}$, while denaturation

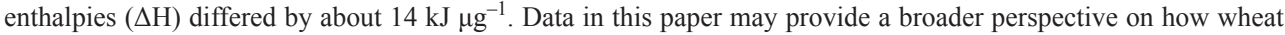
proteins are affected by the extraction method.

Keywords: differential scanning calorimetry (DSC), denaturation, circular dichroism, gluten

Wheat flour is a raw material used worldwide to produce a great diversity of products. In its composition, protein content is a determining factor of the quality and characteristics of the final products (RODRIGUES \& TEIXEIRA, 2010). Some of the main characteristics investigated in wheat flour-based goods are the textural and rheological properties, which are directly affected by the formation of the gluten network that contains the gliadin and glutenin proteins. Gliadins are alcohol-soluble monomeric proteins that form transient bindings by non-covalent interactions. The glutenin fraction consists of varied molecular weight subunits cross-linked by inter- and intramolecular disulfide bonds plus covalent bonds (DHAKA \& KHATKAR, 2016; Ortolan \& Steel, 2017). The non-covalent bonds also aid in the formation of the gluten network, but are weaker and do not play a significant role in the interactions between gluten proteins (LiU \& HsieH, 2008). The amino acid residues cysteine and tyrosine, present in the gliadin and glutenin proteins, help in the formation of the gluten network bonds (PEÑA et al., 2006). The inter- and intramolecular interactions between gluten proteins and other wheat flour compounds are conditions of significance by conferring adequate cohesion, viscosity, and elasticity to wheat flour products (KHATKAR et al., 2013).

Denaturation of the gluten proteins affects the structure and final characteristics of bakery products (WANG et al., 2014). Because of processing, thermal denaturation is the main cause of these irreversible changes in most processed foods containing wheat flour (RELKIN \& LAUnAY, 1990). In this sense, it is important to identify how proteins are affected when

* To whom correspondence should be addressed.

E-mail: lizks3001@yahoo.com.br 
exposed to processes and extraction methods. This can be done by evaluating conformation, yield, molecular weight, and thermal profile of the proteins.

Although studies have verified the physical parameters of wheat gluten proteins, only a few provide information necessary to understand the effect of different extraction and purification methods, together with analyses of thermal events (FALCÃO-RoDRIGUES et al., 2005; WANG et al., 2014). In wheat flour products, the differential scanning calorimetry (DSC) is used to investigate thermal parameters of protein denaturation (FALCÃO-RODRIGUES et al., 2005) during freezing and storage (WANG et al., 2014). In this study, four different methods of wheat protein extraction were evaluated focusing on the glutenin rich fractions and the final quality of this protein in terms of denaturation, indirect yield, molecular weight, conformation, and thermal profile.

\section{Materials and methods}

\subsection{Materials}

Wheat flour of the BRS-PARRUDO cultivar, provided by EMBRAPA (Passo Fundo, Brasil), was used throughout the work. The average value of gluten strength of this cultivar is $324 \times 10^{-4} \mathrm{~J}$, which makes it a flour of strong gluten grade. The chemicals used in this work were of analytical grade.

\subsection{Extraction of proteins}

1.2.1. Standard extraction method (St-M). The separation procedure was performed according to the methodology described by LEÓN and co-workers (2003). This procedure consists of a stepwise extraction of albumin, globulin, gliadin, and glutenin fractions, in this sequence, using different solvents. For the first extraction (albumin separation), wheat flour (20 g) was suspended in distilled deionized water $(100 \mathrm{ml})$, and the mixture was stirred for $30 \mathrm{~min}$ using a magnetic stirrer (100 to 150 r.p.m.). The suspension was centrifuged (EXCELSA II, FANEM, São Paulo, Brazil) at 5000 r.p.m. for 10 min. Subsequent extractions used the precipitate of a previous extraction applying the same conditions mentioned above. Tris- $\mathrm{HCl}$ solution $(\mathrm{pH} 8,50 \mathrm{mM})$ in the presence of $\mathrm{KCl}(100 \mathrm{mM})$ and EDTA $(5 \mathrm{mM})$ was used for globulin extraction. For gliadin extraction, an aqueous solution of 1-propanol $(50 \% \mathrm{v} / \mathrm{v})$ was used. Finally, for extracting glutenin (SDS-soluble proteins), an aqueous solution of 1-propanol $(50 \% \mathrm{v} / \mathrm{v})$ containing $1 \%$ SDS $(\mathrm{v} / \mathrm{v})$ was used. Following each extraction, the precipitate obtained after centrifugation was washed with the proper solvent, and the supernatant consisted of a protein-specific phase.

1.2.2. Extraction with addition of dithiothreitol (DTT) solution (S-DTT). This extraction procedure was carried out using the St-M described in section 1.2.1, with modifications. For all solutions, for the solubilisation of precipitates, $1 \mathrm{mM}$ of DTT was added to the specific solvent.

1.2.3. Decantation extraction method (Dec-M). Dec-M consists of performing a St-M (section 1.2.1) with modifications in the solvent volume, method of mixing, and inclusion of a decantation period. For the same initial amount of sample (20 g wheat flour), $600 \mathrm{ml}$ of 
solvent was used in the extraction of each protein fractions (albumin, globulin, gliadin, and glutenin). Specific modifications were performed as listed below.

1. Albumin-rich fraction: Slow mixing was performed using a glass stick, followed by a rest for $15 \mathrm{~min}$ (decantation) and discharge of the supernatant. This procedure was repeated 10 times for the decanted material.

2. Globulin-rich fraction: The system (precipitate from extraction $1+$ Tris-hydrochloride/ $\mathrm{KCl}$ /EDTA) was slowly stirred, and the suspension was kept at rest for one hour. The precipitate was used in the third extraction (gliadin extraction).

3. Gliadin-rich fraction: The mixture (precipitate from extraction $2+1$-propanol) was manually stirred prior to centrifugation. The supernatant was stored, and the precipitate was saved for glutenin extraction.

4. Glutenin-rich fraction: Precipitate from extraction 3 was mechanically stirred at 40 r.p.m. for 5 min with the 1-propanol + SDS solution.

1.2.4. Direct extraction method (Dir-M). In the Dir-M, the last extraction procedure used in the St-M (section 2.2.1) was directly applied to the wheat flour sample, without performing those previous steps of protein purification.

The final precipitates obtained from all extractions were discarded. The extracted solution containing the glutenin-rich fractions were stored under refrigeration $\left(5^{\circ} \mathrm{C}\right)$ and then used for analysis.

\subsection{Evaluation and quantification of proteins and molecular weight}

The quantification of the glutenin-rich fractions was carried out according to the method of BRADFORD (1976). The standard curve was constructed using bovine serum albumin in the range of 0.6 to $10 \mu \mathrm{g}$.

The molecular weight of the molecules in these fractions were estimated by denaturing polyacrylamide gel electrophoresis (SDS-PAGE) using the protocol of LAEMmLi (1970). The separation gel used contained $12 \%(\mathrm{w} / \mathrm{v})$ acrylamide, while the stacking gel contained $4 \%$ $(\mathrm{w} / \mathrm{v})$. All samples received a buffer solution ( $2 \%$ SDS, $10 \%$ glycerol, $0.01 \%$ bromophenol blue, $0.0625 \mathrm{~mol} \mathrm{l}^{-1} \mathrm{Tris}-\mathrm{HCl} \mathrm{pH} 6.8,5 \% \beta$-mercaptoethanol) and were heated at $80{ }^{\circ} \mathrm{C}$ for 5 min before application. Laemmli buffer $\left(3 \mathrm{~g} \mathrm{l}^{-1}\right.$ Tris-base, $14 \mathrm{~g} \mathrm{l}^{-1}$ glycine, $\left.1 \mathrm{~g} \mathrm{l}^{-1} \mathrm{SDS}\right)$ was used in the vessel. The molecular weight ladder used was LMW Calibration Kit (GE Life sciences). After electrophoresis, proteins in the gel were stained with Coomassie Blue R-250 dye and distained in a $50 \%(\mathrm{v} / \mathrm{v})$ methanol $+10 \%(\mathrm{v} / \mathrm{v})$ acetic acid solution.

\subsection{Circular dichroism (CD)}

$\mathrm{CD}$ analyses were carried out to evaluate possible denaturation of glutenin-rich fractions after extraction. A J-815 CD spectrometer (Jasco International CO, Tokyo, Japan) equipped with a temperature control unit was used. Quartz cuvettes $(0.01 \times 0.01 \times 1 \mathrm{~cm})$ were used as a container, and nitrogen at a flow rate of $101 \mathrm{~min}^{-1}$ was used as a purge gas. The secondary structure composition was estimated by CD-Pro software using the CONTIN-LL algorithm (Sreerama \& Woody, 2000). 


\subsection{Thermal profile}

A DSC 8500 from Perkin Elmer was used in all analyses. A standard thermal run was built starting from 20 to $80{ }^{\circ} \mathrm{C}$ using a heating rate of $2{ }^{\circ} \mathrm{C} \mathrm{min}^{-1}$. Nitrogen at flow rate of $50 \mathrm{ml}$ $\min ^{-1}$ was used as purge gas. The DSC was calibrated using indium standard reference (purity $>99.99 \%$ ) (melting temperature: $156.60{ }^{\circ} \mathrm{C}$ and transition energy: $28.45 \mathrm{~J} \mathrm{~g}^{-1}$ ). Standard open aluminium pans with an internal volume of $20 \mu \mathrm{l}$ (Perkin Elmer) were used as supports. Around $18 \mathrm{mg}$ of protein solution of the glutenin rich fractions obtained after each extraction were used in the DSC experiments. The denaturation temperature and enthalpy were obtained using the software Pyris Manager (v. 2009, Perkin Elmer). Mean values were subjected to one-way ANOVA followed by Tukey's post-hoc test when presenting significance at a 95\% level. Variances were tested using the software Statistica v. 10.0 (Statsoft, Tulsa, USA). All analyses were performed in triplicate.

To verify the influence of the impurities in the thermal profile of glutenin-rich fractions of wheat flour, a dialysis process was performed for samples obtained by the S-DTT method. The dialysis was performed in sealed membrane tubes (12-14 kDa MWCO, Sigma) at $5{ }^{\circ} \mathrm{C}$ in 11 of distilled water under magnetic stirring for 16 hours, prior to thermal analyses.

\section{Results and discussion}

\subsection{Analyses of glutenin-rich fractions}

2.1.1. Protein molecular weight and quantification. Glutenins are divided into two distinct groups of proteins in an electrophoresis gel (Fig. 1). The first group has weights ranging from 90 to $140 \mathrm{kDa}$ (glutenins of high molecular weight), and the second has molecular weights between 30 and $50 \mathrm{kDa}$ (glutenins of low molecular weight) (LARRÉ et al., 1997; VERBRUGGEN et al., 1998). The apparent molecular weights of the bands found in the electrophoresis gel were estimated using the migration of the molecular weight marker as a standard, resulting in $86.7 \pm 2.9 \mathrm{kDa}$, probably for the glutenin fractions of high molecular weight, and in the ranges of $48.25 \pm 0.49 \mathrm{kDa}$ and $39.1 \pm 0.45 \mathrm{kDa}$ for the glutenin fractions of low molecular weight. Thus, it was possible to delimit the regions of the gel containing bands corresponding to the two groups of glutenins, which are highlighted in Figure 1. Bands of the glutenin-rich fractions were seen for St-M and S-DTT samples due to the high concentration of proteins, proving a higher selectivity in the extraction methods employed.

Beside the existence of bands for glutenins of high and low molecular weights, proteins with molecular weights between 14 and $21 \mathrm{kDa}$ were also detected. These bands probably correspond to non-gluten-forming proteins such as albumin and globulin, which were not completely removed in the previous steps. Direct extraction is the method that showed more intense bands in the range of low molecular weights, confirming higher contamination by other non-glutenin proteins. This may have occurred because the extraction method was performed in a single step, skipping previous extracting/washing steps that improve the purification of glutenin concerning other types of protein. No band was observed in the electrophoresis analysis of the extract obtained in Dec-M due to the low concentration of proteins in the glutenin-rich fractions, indicating that the method is not suitable for extracting glutenins from wheat flour. 


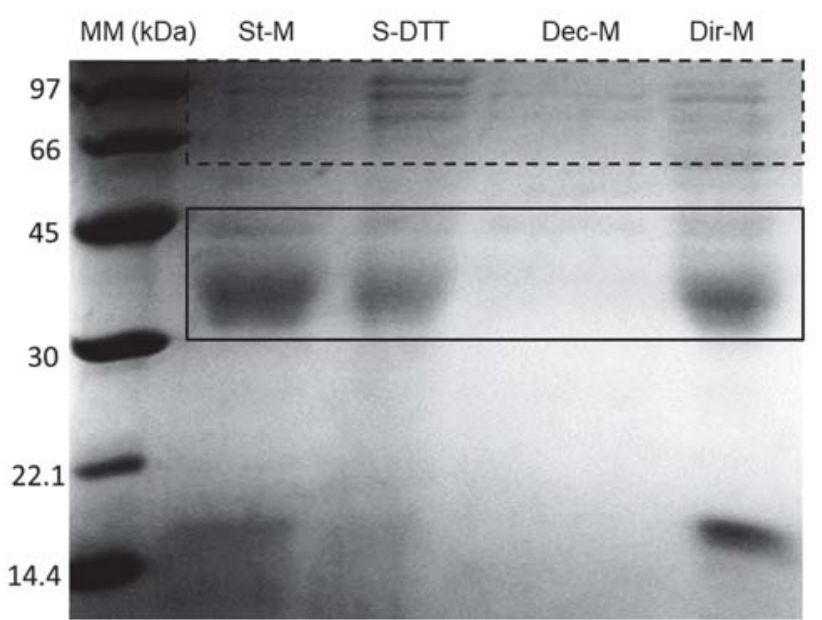

Fig. 1. Glutenin-rich fractions of different methods of extraction by SDS-PAGE. MM shows the molecular weight marker $(\mathrm{kDa})$. Dashed lines: glutenin fractions of high molecular weight. Continuous lines: glutenin-rich fractions of low molecular weight.

Dir-M: direct extraction method; St-M: standard extraction method; S-DTT: extraction with addition of dithiothreitol (DTT) solution; Dec-M: decantation extraction method

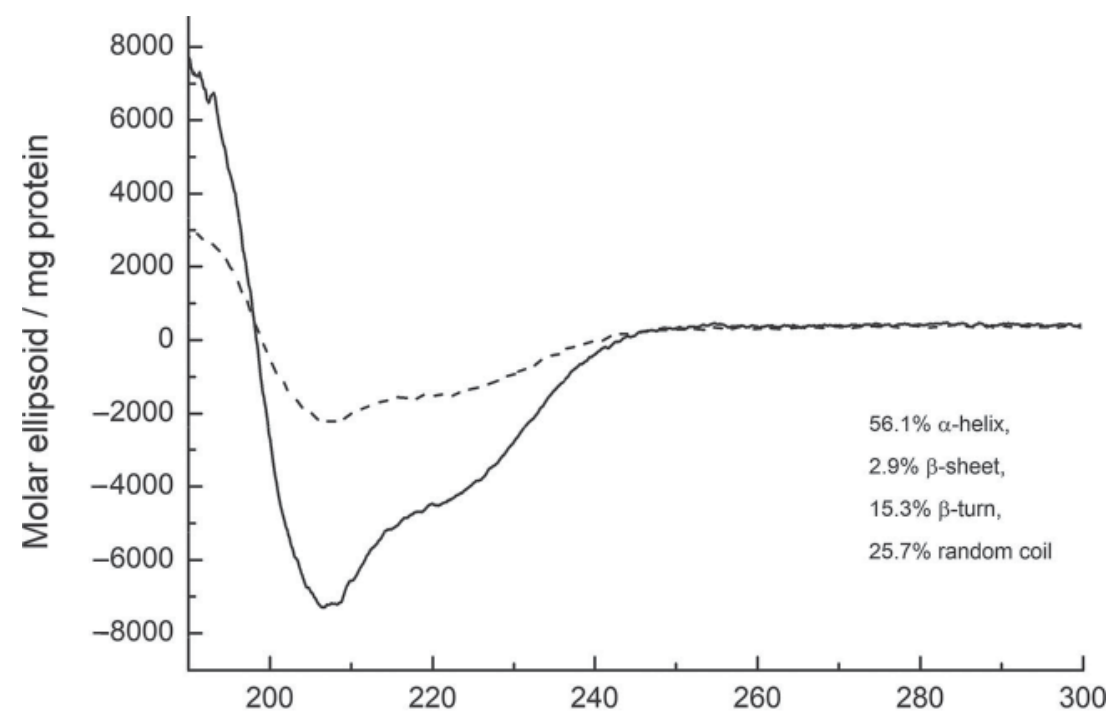

Fig. 2. CD spectrum of the glutenin-rich fractions extracted by standard extraction $\left(0.002 \mathrm{mg} \mathrm{ml}^{-1}\right)$ and the DTT extraction $\left(0.003 \mathrm{mg} \mathrm{ml}^{-1}\right) \mathrm{T}=20^{\circ} \mathrm{C}$

_ : standard extraction (St-M); ----: extraction with addition of DTT (S-DTT)

The glutenin-rich fractions obtained by both St-M and S-DTT presented lower protein concentration when compared with Dir-M $\left(8.779 \pm 0.001 \mathrm{mg} \mathrm{ml}^{-1}\right)$. St-M showed $0.200 \pm 0.004$ $\mathrm{mg} \mathrm{ml}^{-1}$ of proteins. The incorporation of DTT in S-DTT allowed a $50 \%$ increase in protein yield, resulting in $0.304 \pm 0.005 \mathrm{mg} \mathrm{m}^{-1}$ (Table 1). As the other two methods showed inferior results, they were not used in glutenin quantification. 
Table 1. Concentration of the glutenin-rich fractions for each extraction method

\begin{tabular}{lc}
\hline Method of extraction & Concentration $\left(\mathrm{mg} \mathrm{ml}^{-1}\right)$ \\
\hline Dir-M & $8.779 \pm 0.001$ \\
St-M & $0.200 \pm 0.004$ \\
S-DTT & $0.304 \pm 0.005$ \\
Dec-M & $0.085 \pm 0.013$ \\
\hline
\end{tabular}

Dir-M: direct extraction method; St-M: standard extraction method; S-DTT: extraction with addition of dithiothreitol (DTT) solution; Dec-M: decantation extraction method

2.1.2. CD analysis. As proteins obtained by St-M and S-DTT presented characteristic bands, with low content of protein contaminants, they were chosen to be analysed by CD. The extracted glutenin rich fractions were kept in the same extraction solution to avoid precipitation of the sample.

The characteristic spectra of denatured proteins present large-amplitude negative peaks at 190-200 nm. For an all $\alpha$-helix conformation, two negative bands of similar amplitude at $222 \mathrm{~nm}$ and $208 \mathrm{~nm}$ and a positive band at $\sim 190 \mathrm{~nm}$ should be observed. Finally, for $\beta$-sheet protein, a negative band in the range of $210-220 \mathrm{~nm}$ and a positive band in the range of 195-200 nm are seen (CORRÊA \& RAMOS, 2009). The glutenin-rich fraction samples CD spectra are presented in Figure 2. We found a higher percentage of the $\alpha$-helix $(56.1 \%)$ rather than $\beta$-sheet $(2.9 \%)$, $\beta$-turn (15.3\%), and random coil $(25.7 \%)$. No difference was observed in the composition of the secondary structure of the protein obtained using both methodologies (St-M and S-DTT). However, the intensity of the signal was smaller for the sample obtained by DTT addition. Therefore, for both extraction methods, the solvents, and conditions used were not drastic enough to cause protein denaturation. According to DHAKA and KHATKAR (2016), the secondary structure of gluten protein is related to the quality of the wheat flour. The composition of the secondary structure obtained in this study may help to understand food products produced with BRS-Parrudo wheat.

\subsection{Thermal profile of fractions rich in glutenin}

The thermal profile of the gluten-forming proteins is a suitable parameter for evaluation of wheat flour quality and its derived products. The DSC curves of the glutenin-rich fractions obtained by St-M, Dir-M, S-DTT, and dialyzed S-DTT are shown in Figures 3 and 4. Table 2 shows the mean values of denaturation temperature and denaturation enthalpy. The thermal profiles and events obtained showed that the data were reproducible regarding peak formation characteristics.

Table 2. Temperature of denaturation $\left(\mathrm{T}_{\mathrm{d}}\right)$ and enthalpy of denaturation $\left(\Delta \mathrm{H}_{\mathrm{d}}\right)$ of the glutenin-rich fractions

\begin{tabular}{lcc}
\hline Method of extraction & $\mathrm{T}_{\mathrm{d}}\left({ }^{\circ} \mathrm{C}\right)$ & $\Delta \mathrm{H}_{\mathrm{d}}\left(\mathrm{J} \mathrm{g}^{-1}\right)$ \\
\hline Dir-M & $67.22 \pm 0.52^{\mathrm{a}}$ & $-10.80 \pm 3.11^{\mathrm{b}}$ \\
St_M & $64.55 \pm 0.61^{\mathrm{a}}$ & $-3.95 \pm 1.02^{\mathrm{a}}$ \\
S-DTT & $65.32 \pm 1.95^{\mathrm{a}}$ & $-12.81 \pm 0.58^{\mathrm{b}}$ \\
S-DTT dialyzed & $65.92 \pm 1.68^{\mathrm{a}}$ & $-17.65 \pm 1.16^{\mathrm{c}}$ \\
\hline
\end{tabular}

Dir-M etc.: see Table 1. Means followed by the same letters in the column do not differ at $95 \%$ confidence level according to Tukey's post-hoc test. 


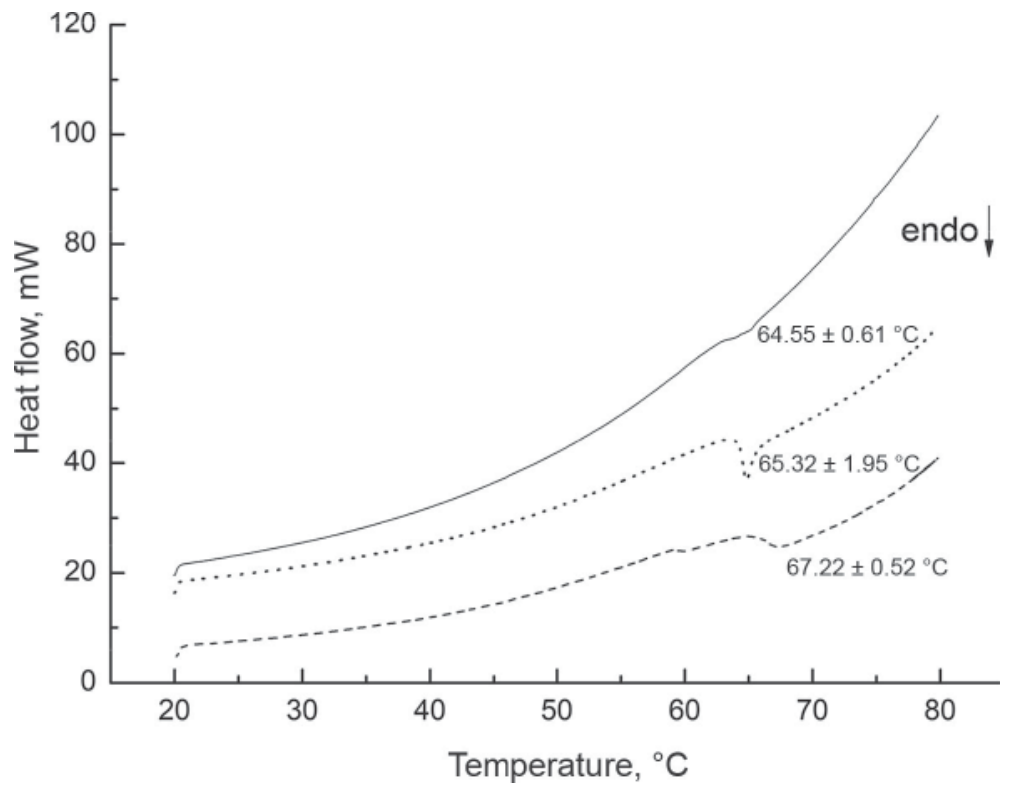

Fig. 3. DSC curve of the glutenin-rich fractions ----: direct extraction; __

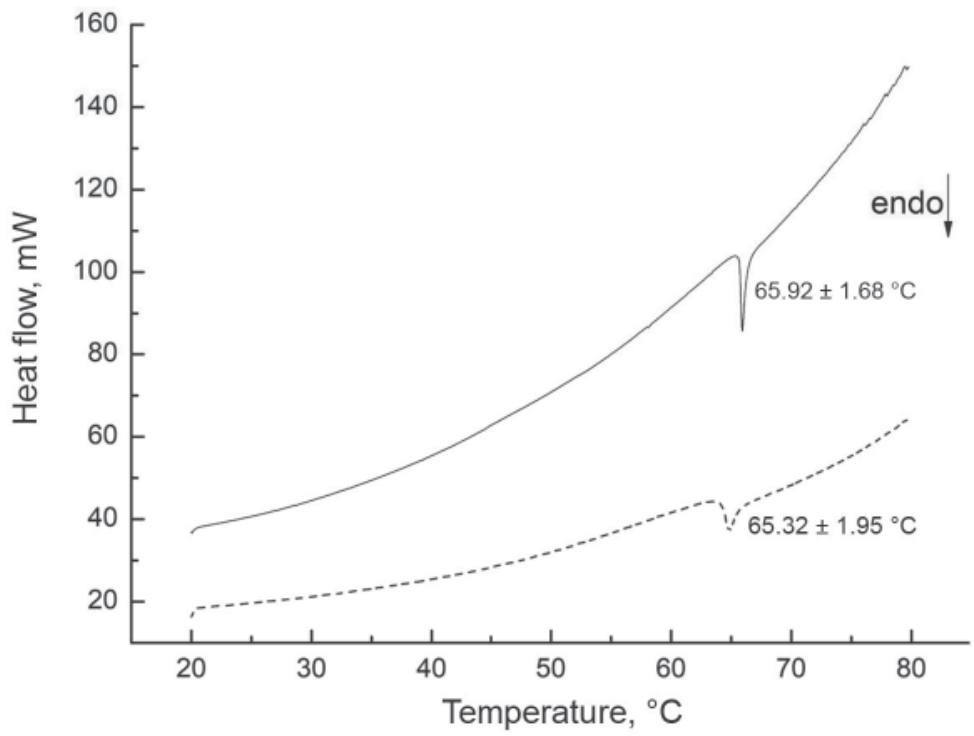

Fig. 4. Thermal profile of samples obtained by DTT-M before and after dialysis ----: DTT extraction; __ _ DTT extraction - dialyzed

No thermal events were observed in the DSC analyses performed with the glutenin-rich fractions obtained by Dec-M. This probably occurred due to the low concentration of the glutenin-rich fractions, which were also not present in the electrophoresis gel bands, 
confirming the absence of glutenin in the extract. Glutenin is known for presenting an endothermic peak at approximately $64{ }^{\circ} \mathrm{C}$ (LEóN et al., 2003), which is following the results obtained in this study.

The sample obtained by Dir-M presented a large amplitude peak, as can be observed in Figure 3, which is a characteristic of sample contamination, probably by other proteins (as observed in electrophoresis analysis). Samples obtained by S-DTT showed the most prominent and defined peaks. Also, they presented higher denaturation enthalpy in comparison with the sample obtained by St-M. This observation is linked to the higher extraction of glutenin achieved by the method in which DTT was applied.

To eliminate impurities from the sample and to refine the results of the best method performed so far, dialyzes were conducted in samples obtained by S-DTT. As shown in Figure 4, the dialysis process produced sharper and more elongated peaks. This shape indicates a higher resolution and is a result of higher glutenin purity in the samples. The $\Delta \mathrm{H}_{\mathrm{d}}$ values of the dialyzed sample were higher than the non-dialyzed ones $\left(12.68 \pm 0.44 \mathrm{~J} \mathrm{~g}^{-1}\right.$ and $17.82 \pm 1.04 \mathrm{~J} \mathrm{~g}^{-1}$, respectively). No significant differences in the temperatures of denaturation obtained before and after dialysis $\left(65.32 \pm 1.95{ }^{\circ} \mathrm{C}\right.$ and $65.92 \pm 1.68{ }^{\circ} \mathrm{C}$, respectively) were observed (Table 1). For more pure and intact protein fractions, higher energy was needed to achieve denaturation. These results are in agreement with results of DHAKA and KHATKAR (2016) and FALCÃo-RODRIGUES and co-workers (2005), who reported that the more ordered the protein's secondary structure, the higher the energy needed for denaturation processes.

\section{Conclusions}

This work aimed to evaluate different methods of glutenin extraction from wheat flour. The addition of DTT in a standard method of extraction was the most efficient extraction procedure. For this method, no denaturation of the glutenin-rich fractions was observed during the extraction process. For the protein fraction extracted by S-DTT, the denaturation temperature and the enthalpy of denaturation showed well-defined peaks $\left(65.15 \pm 1.74{ }^{\circ} \mathrm{C}\right.$ and $-12.68 \pm 0.44 \mathrm{~J} \mathrm{~g}^{-1}$, respectively). The method of extraction S-DTT followed by dialyzes is a protocol that should be considered for extracting quality glutenin from wheat gluten. The results obtained from the thermal properties of the glutenin rich fractions may contribute in the future to a better understanding of other properties that involve the protein fractions of wheat flour for the development of bakery products.

The authors are grateful for the research grants provided by CAPES and CNPq (grant no. 310905/2015-0), the support from the Food Engineering Graduate Programme (Federal University of Paraná, Curitiba, Brazil), and the supply of wheat flour samples from Embrapa Wheat.

\section{References}

Bradford, M.M. (1976): A rapid and sensitive method for the quantitation of microgram quantities of protein utilizing the principle of protein-dye binding. Anal. Biochem., 72, 248-254.

CorrêA, D.H.A. \& Ramos, C.H.I. (2009): The use of circular dichroism spectroscopy to study protein folding, form and function. Afr. J. Biochem. Res. (AJBR), 3, 164-173. 
DHAKa, V. \& KHATKaR, B.S. (2016): Microstructural, thermal and IR spectroscopy characterization of wheat gluten and its sub fractions. J. Food Sci. Tech., 53, 3356-3363.

Falcão-rodrigues, M.M., Moldão-martins, M. \& Beirão-da-costa, M.L. (2005): Thermal properties of gluten proteins of two soft wheat varieties. Food Chem., 93, 459-465.

Khatkar, B.S., Barak, S. \& Mudgil, D. (2013): Effects of gliadin addition on the rheological, microscopic and thermal characteristics of wheat gluten. Int. J. Biol. Macromol., 53, 38-41.

LAEMmLi, U.K. (1970): Cleavage of structural proteins during the assembly of the head of bacteriophage T4. Nature, 227, 680-685.

Larré, C., Nicolas, Y., Desserme, C., Courcoux, P. \& Popineau, Y. (1997): Preparative separation of high and low molecular weight subunits of glutenin from wheat. J. Cereal Sci., 25, 143-150.

León, A., Rosell, C.M. \& Benedito de Barber, C. (2003): A differential scanning calorimetry study of wheat proteins. Eur. Food Res. Technol., 217, 13-16.

LiU, K. \& HsieH, F-H. (2008): Protein-protein interactions during high-moisture extrusion for fibrous meat analogues and comparison of protein solubility methods using different solvent systems. J. Agr. Food Chem., 56, 26812687.

Ortolan, F. \& Steel, C.J. (2017): Protein characteristics that affect the quality of vital wheat gluten to be used in baking: A review. Compr. Rev. Food Sci. F., 16, 369-381.

Peña, E., Bernardo, A., Soler, C. \& Jouve, N. (2006): Do tyrosine crosslinks contribute to the formation of the gluten network in common wheat (Triticum aestivum L.) dough? J. Cereal Sci., 44, 144-153.

Relkin, P. \& Launay, B. (1990): Concentration effects on the kinetics of $\beta$-lactoglobulin heat denaturation: A differential scanning calorimetric study. Food Hydrocolloids, 4, 19-32.

Rodrigues, O. \& Teixeira, M.C.C. (2010): Bases ecofisiológicas para manutenção da qualidade do trigo. (Ecophysiological bases for maintenance of wheat quality). Passo Fundo, Brasil: Embrapa Trigo. 84 pages.

Sreerama, N. \& Woody, R.W. (2000): Estimation of protein secondary structure from circular dichroism spectra: Comparison of CONTIN, SELCON, and CDSSTR methods with an expanded reference set. Anal. Biochem., $287,252-260$

Verbruggen, I.M., Veraverbeke, W.S., Vandamme, A. \& Delcour, J.A. (1998): Simultaneous isolation of wheat high molecular weight and low molecular weight glutenin subunits. J. Cereal Sci., 28, 25-32.

Wang, P., Xu, L., Nikoo, M., Ocen, D., Wu, F. \& Xu, X. (2014): Effect of frozen storage on the conformational, thermal and microscopic properties of gluten: Comparative studies on gluten-, glutenin- and gliadin-rich fractions. Food Hydrocolloids, 35, 238-246. 